Transformational leaders inspire, energize, and intellectually stimulate their employees. The author argues that through training, managers can learn the techniques and obtain the qualities they need to become transformational leaders.

\title{
From Transactional to Transformational Leadership: Learning to Share the Vision
}

\author{
BERNARD M. BASS
}

S ir Edmund Hillary of Mount Everest fame liked to tell a story about one of Captain Robert Falcon Scott's earlier attempts, from 1901 to 1904, to reach the South Pole. Scott led an expedition made up of men from the Royal Navy and the merchant marine, as well as a group of scientists. Scott had considerable trouble dealing with the merchant marine personnel, who were unaccustomed to the rigid discipline of Scott's Royal Navy. Scott wanted to send one seaman home because he would not take orders, but the seaman refused, arguing that he had signed a contract and knew his rights. Since the seaman was not subject to Royal Navy disciplinary action, Scott did not know what to do. Then Ernest Shackleton, a merchant navy officer in Scott's party, calmly informed the seaman that he, the seaman, was returning to Britain. Again the seaman refused-and Shackleton knocked him to the ship's deck. After another refusal, followed by a second flooring, the seaman decided he would return home. Scott later became one of the victims of his own inadequacies as a leader in his 1911 race to the South Pole. Shackleton went on to lead many memorable expeditions; once, seeking help for the rest of his party, who were stranded on the Antarctic Coast, he journeyed with a small crew in a small open boat from the edge of Antarctica to South Georgia Island.

\section{LEADERSHIP TODAY}

Most relationships between supervisors and their employees are quite different today. Few managers depend mainly on their legitimate power, as Scott did, or on their coercive power, as Shackleton did, to persuade people to do as they're told. Rather, managers engage in a transaction with their employees: They explain what is required of 


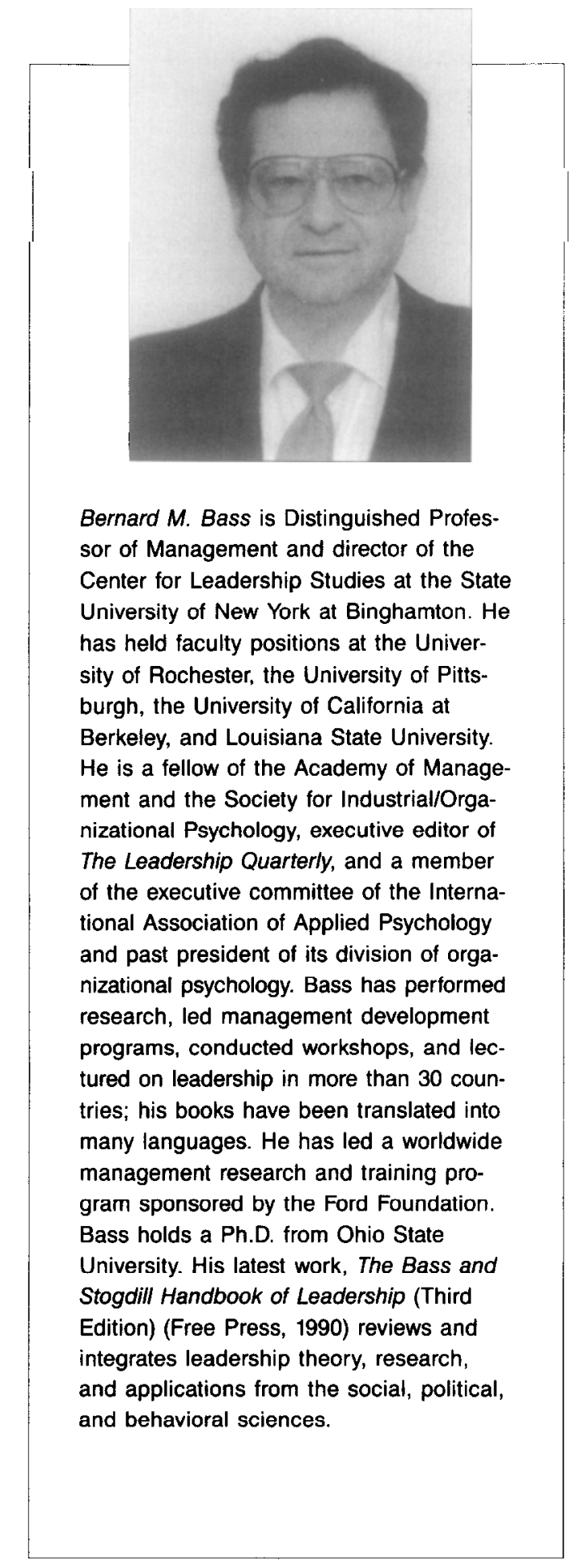

them and what compensation they will receive if they fulfill these requirements.

A shift in management style at Xerox's Reprographic Business Group (RBG) provides a good example. In the first step toward establishing management in which managers take the initiative and show consideration for others, 44 specific, effective management behaviors were identified. Two factors that characterize modern leadership were found in many of these behaviors. One factor-initialing and organizing work - concentrates on accomplishing the tasks at hand. The second factor-showing consideration for employees - focuses on satisfying the self-interest of those who do good work. The leader gets things done by making, and fulfilling, promises of recognition, pay increases, and advancement for employees who perform well. By contrast, employees who do not do good work are penalized. This transaction or exchange - this promise and reward for good performance, or threat and discipline for poor performance-characterizes effective leadership. These kinds of transactions took place in most of the effective 44 leadership behaviors identified at Xerox's RBG. This kind of leadership, which is based on transactions between manager and employees, is called "transactional leadership."

In many instances, however, such transactional leadership is a prescription for mediocrity. This is particularly true if the leader relies heavily on passive management-by-exception, intervening with his or her group only when procedures and standards for accomplishing tasks are not being met. My colleagues and I have arrived at this surprising but consistent finding in a number of research analyses. Such a manager espouses the popular adage, "If it ain't broken, don't fix it." He or she stands in back of the caboose of a moving freight train and says, "Now I know where we are going." This kind of manager may use 
disciplinary threats to bring a group's performance up to standards - a technique that is ineffective and, in the long run, likely to be counterproductive.

Moreover, whether the promise of rewards or the avoidance of penalties motivates the employees depends on whether the leader has control of the rewards or penalties, and on whether the employees want the rewards or fear the penalties. In many organizations, pay increases depend mainly on seniority, and promotions depend on qualifications and policies about which the leader has little to say. The breaking of regulations may be the main cause of penalties. Many an executive has found his or her hands tied by contract provisions, organizational politics, and inadequate resources.

\section{TRANSFORMATIONAL LEADERSHIP}

Superior leadership performance - transformational leadership - occurs when leaders broaden and elevate the interests of their employees, when they generate awareness and acceptance of the purposes and mission of the group, and when they stir their employees to look beyond their own self-interest for the good of the group. Transformational leaders achieve these results in one or more ways: They may be charismatic to their followers and thus inspire them; they may meet the emotional needs of each employee; and/or they may intellectually stimulate employees. Exhibit 1 lists the characteristics of transformational and transactional leadership; these listings are based on the findings of a series of surveys and on clinical and case evidence.

Attaining charisma in the eyes of one's employees is central to succeeding as a transformational leader. Charismatic leaders have great power and influence. Employees want to identify with them, and they have a high degree of trust and confidence in them. Charismatic leaders inspire and excite their employees with the idea that they may be able to accomplish great things with extra effort. Further, transformational leaders are individually considerate, that is, they pay close attention to differences among their employees; they act as mentors to those who need help to grow and develop. Intellectual stimulation of employees is a third factor in transformational leadership. Intellectually stimulating leaders are willing and able to show their employees new ways of looking at old problems, to teach them to see difficulties as problems to be solved, and to emphasize rational solutions. Such a leader was Lorenz Iversen, a former president of the Mesta Machine Company, who said to his employees, "We got this job because you're the best mechanics in the world!" He practiced management-by-walking-around and stimulated the development of many of Mesta's patented inventions. He is remembered for instilling pride and commitment in his employees.

\section{THE BIG PAYOFF}

Managers who behave like transformational leaders are more likely to be seen by their colleagues and employees as satisfying and effective leaders than are those who behave like transactional leaders, according to their colleagues', supervisors', and employees' responses on the Multifactor Leadership Questionnaire (MLQ). Similar results have been found in various organizational settings. Leaders studied have come from an extremely broad variety of organizations: chief executive officers and senior and middle level managers in business and industrial firms in the United States, Canada, Japan, and India; research and development project leaders; American, Canadian, and British Army field grade offi- 


\section{TRANSFORMATIONAL LEADER}

Charisma: Provides vision and sense of mission, instills pride, gains respect and trust.

Inspiration: Communicates high expectations, uses symbols to focus efforts, expresses important purposes in simple ways.

Intellectual Stimulation: Promotes intelligence, rationality, and careful problem solving.

Individualized Consideration: Gives personal attention, treats each employee individually, coaches, advises.

\section{TRANSACTIONAL LEADER}

Contingent Reward: Contracts exchange of rewards for effort, promises rewards for good performance, recognizes accomplishments.

Management by Exception (active): Watches and searches for deviations from rules and standards, takes corrective action.

Management by Exception (passive): Intervenes only if standards are not met.

Laissez-Faire: Abdicates responsibilities, avoids making decisions.

cers; United States Navy senior officers and junior surface fleet officers; Annapolis midshipmen; educational administrators; and religious leaders.

Moreover, various types of evaluations including performance ratings by both supervisors and direct reports, as well as standard financial measures - have produced a similar correlation between transformational behavior and high ratings. Managers tagged as high performers by their supervisors were also rated, in a separate evaluation by their followers, as more transformational than transactional. Their organizations do better financially. The same pattern emerged between followers' descriptions of shipboard Naval officers and those officers' supervisors' performance appraisals and recommendations for early promotion. And among Methodist ministers, transformational - not transactional-leadership behavior was positively related to high church attendance among congregants and growth in church membership.

Results were the same for evaluation of 22 team performance in complex business simu- lations. Considerable credit for Boeing's turnaround since its 1969 crisis can be given to its chief executive, T.A. Wilson, who has emphasized technological progress, aggressive marketing, and a willingness to take calculated business risks. The confidence that Boeing employees have in Wilson, and their respect for him as a brilliant engineer and an outstanding leader, have instilled in them great pride in the company and its products.

\section{EXTRA EFFORT FROM BELOW}

Transformational leaders have better relationships with their supervisors and make more of a contribution to the organization than do those who are only transactional. Moreover, employees say that they themselves exert a lot of extra effort on behalf of managers who are transformational leaders. Organizations whose leaders are transactional are less effective than those whose leaders are transformational-particularly if much of the transactional leadership is passive management-by- 
exception (intervening only when standards are not being met). Employees say they exert little effort for such leaders. Nevertheless, leader-follower transactions dependent on contingent reward may also work reasonably well if the leaders can provide rewards that are valued by the followers.

Exhibit 2 illustrates the effect that transformational, as compared with transactional, leadership has on employee effort. The data were collected from 228 employees of 58 managers in a large engineering firm. The managers were ranked according to their leadership factor scores, which were based on descriptions of leaders by their employees and colleagues on the Multifactor Leadership Questionnaire. "Four-star" leaders were those who ranked in the top $25 \%$ on a leadership factor score; "one-star" leaders were among the bottom $25 \%$ of managers on the leadership factor score. From $75 \%$ to $82 \%$ of the "four-star" transformational managers had employees who indicated they frequently exerted extra effort on their jobs. Of the "one-star" transformational managers, only $22 \%$ to $24 \%$ had employees who said they frequently exerted extra effort.

It is interesting to note that, as Exhibit 2 illustrates, being rated as "four-star" rather than "one-star" in transactional leadership did not have the same impact on employees' extra effort as a high rating had for the transformational leaders. Similar findings have emerged from studies of leaders and their immediate employees at a diverse range of organizations, including Digital Equipment Corporation and Federal Express.

\section{DIFFERENT STYLES OF TRANSFORMATIONAL LEADERSHIP}

As noted earlier, certain types of behavior characterize the transformational leader. Yet transformational leaders vary widely in their personal styles. H. Ross Perot is selfeffacing: "I don't look impressive," he says. "To a lot of guys I don't look like I could afford a car." But Perot created the $\$ 2.5$ billion EDS organization from his vision, initiative, emphasis on hard work, and a special organizational culture with strict codes of morality and dress and quasi-military management. His personal involvement in the rescue of two of his employees trapped as hostages in Iran in 1979 is an extreme example of individualized consideration, a transformational factor. Leslie Wexner of The Limited, Inc. enjoys a more flamboyant lifestyle. But like Perot, Wexner converted his vision of a nationwide chain of women's sportswear stores into a reality through his own hard work. He stimulates employee participation in discussions and decisions and encourages them to share his vision of the company's future.

Many on Fortune's list of the ten toughest bosses would not live up to modern behavioral science's prescriptions for the good leader: one who initiates the structure for interaction among his colleagues, and who does so with consideration for their welfare. Nevertheless, these tough bosses are highly successful as a consequence of the transformational qualities they display; Boeing's Wilson is a case in point. Although they do initiate structure and may be considerate of their employees, these leaders succeed through such transformational factors as charisma and the ability and willingness to treat different subordinates differently, as well as by providing intellectual stimulation for the employees. They frequently raise standards, take calculated risks, and get others to join them in their vision of the future. Rather than work within the organizational culture, they challenge and change that culture, as Roger Smith of General Motors Corporation did. Self-determination and self-confidence are characteristic of them. They succeed because of these transfor- 
Exhibit 2

EMPLOYEES' EFFORTS UNDER VARIOUS LEADERS

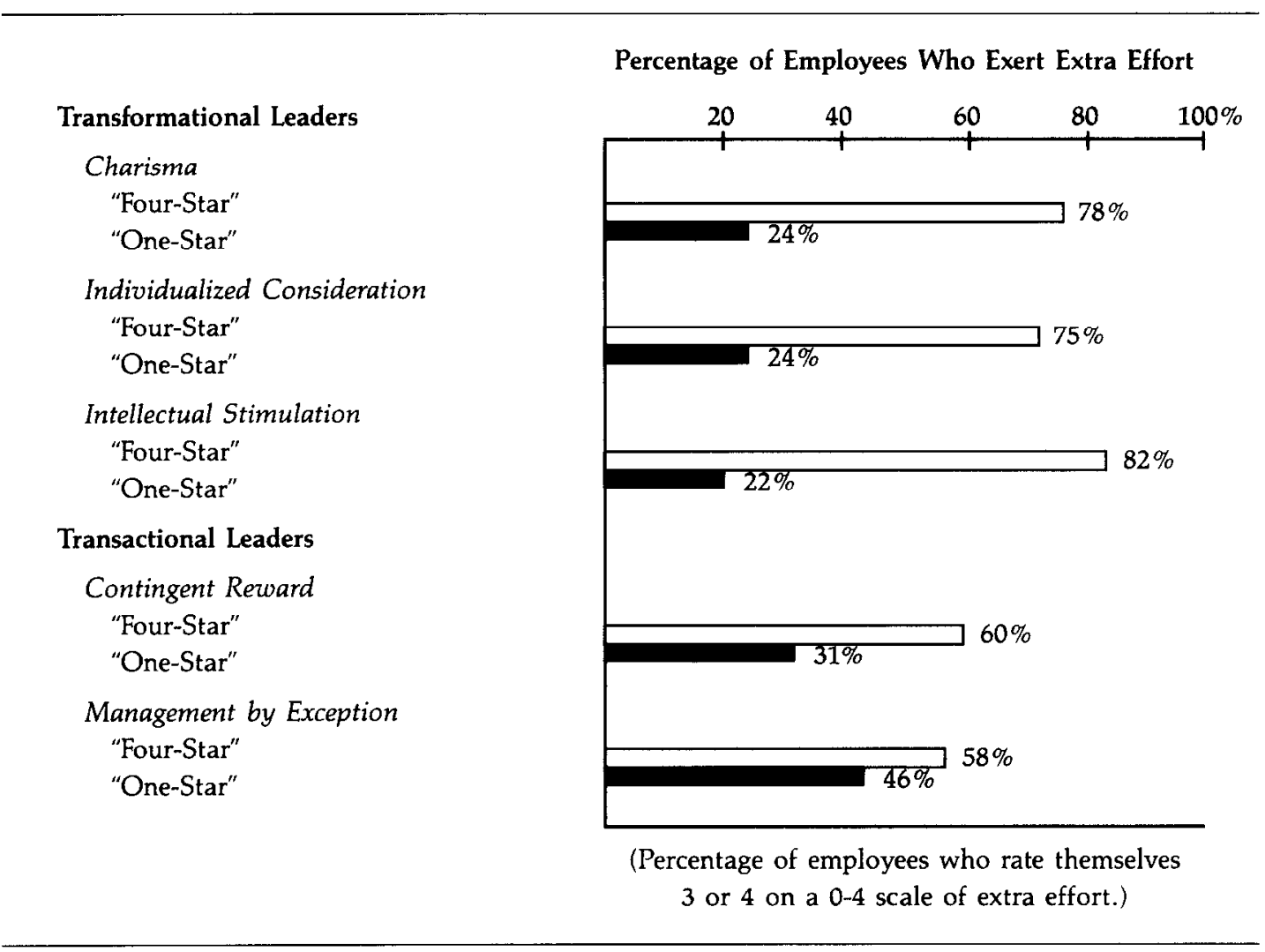

mational elements - even if they, like Wilson, have authoritarian tendencies.

\section{TRANSFORMATTONAL LEADERS MAKE THE DIFFERENCE BETWEEN SUCCESS AND FAILURE}

Fighting with far fewer men and tanks than his enemy had, against superior equipment, Ernst Rommel, the Desert Fox, won a series of victories in 1941 and 1942 against the British in North Africa, until he was overwhelmed at El Alamein. Because he was up front at the scene of the action, he could make more rapid assessments and decisions than could his British counterparts, who stayed 20 miles back in headquarters. This, and his willingness to accept calculated risks, contributed to his legendary speed, surprise, and boldness, as well as to the continuing high morale of his troops.

Napoleon declared that an army of rabbits commanded by a lion could do better than an army of lions commanded by a rabbit. He was not far from the truth. With all due respect to social, economic, political, and market forces, and to human resources policies that affect an organization's health, having a lion-or, in Rommel's case, a fox-in command rather than a rabbit frequently means success for the organization. Lee Iacocca of Chrysler Corporation and John Welch of General Electric, who have become folk heroes (or 
folk devils, to some), are contemporary examples of the importance of transformational leaders to their organizations.

Leadership makes its presence felt throughout the organization and its activities. We have found that employees not only do a better job when they believe their supervisors are transformational leaders, but they also are much more satisfied with the company's performance appraisal system. Likewise, mass communications directed toward individual employees are much more likely to have an impact if the messages are reinforced face-toface by their supervisors at all organizational levels.

Transformational leadership should be encouraged, for it can make a big difference in the firm's performance at all levels. Managers need to do more than focus on the exchange of material, social, and personal benefits for services satisfactorily rendered. The charismatic leader, like the flamboyant Ted Turner of Turner Broadcasting System, Inc. can instill a sense of mission; the individually considerate leader, like the shy and self-effacing Roberto Goizueta of the Coca Cola Corporation, can lead employees to take an interest in higher-level concerns; the intellectually stimulating leader, like the innovative Roger Smith at General Motors Corporation, can articulate a shared vision of jointly acceptable possibilities. This is not to say that transformational leaders are always prosocial in their efforts, for some fulfill grandiose dreams at the expense of their followers.

Despite the many successes with management development programs and the leadership development programs in our military academies, many executives still feel that leadership is like the weather-something to talk about, but about which not much can be done. Others say leadership ability is mystical-one needs to be born with it.

In fact, much can be done to improve leadership in an organization and to change the presiding style from transactional to transformational. The overall amount of transformational leadership in an organization can be increased substantially by suitable organizational and human resources policies. The new model of transformational leadership presents opportunities for enhancing a corporation's image and for improving its success in recruitment, selection, and promotion. This model also has implications for the organization's training and development activities and for the design of its jobs and organizational structure.

\section{Implications for Corporate Image}

It is no accident that many of the firms identified in Tom Peters and Robert Waterman's In Search of Excellence (Warner Books, 1982) as excellently managed have large numbers of transformational leaders. Conversely, the poorly managed "dinosaurs" among the firms they describe need to implement a lot more transformational leadership. A firm that is permeated with transformational leadership from top to bottom conveys to its own personnel as well as to customers, suppliers, financial backers, and the community at large that it has its eyes on the future; is confident; has personnel who are pulling together for the common good; and places a premium on its intellectual resources and flexibility and on the development of its people.

\section{Implications for Recruiting}

Increasing transformational leadership within the organization may help in recruitment. Candidates are likely to be attracted to an organization whose CEO is charismatic and enjoys a public image as a confident, suc- 
cessful, optimistic, dynamic leader. In addition, prospects are likely to be attracted by interview experiences with other members of management who exhibit individualized consideration. More intelligent prospects will be particularly impressed with intellectually stimulating contacts they make during the recruiting and hiring process.

Implications for Selection, Promotion, and Transfer

Since we can identify and measure the factors associated with transformational leadership, these factors should be incorporated into managerial assessment, selection, placement, and guidance programs - along with related assessments of relevant personal dimensions and individual differences. Somewhat more transformational leadership is generally expected and found as managers move to successively higher levels in the organization, but it is reasonable to expect that an individual's performance at one level will be similar to his or her performance at the next. Direct reports, peers, and/or supervisors can be asked to describe the manager's current leadership with the Multifactor Leadership Questionnaire; their responses should be considered when decisions are made regarding a manager's promotion or transfer into a position of greater supervisory responsibility. Feedback from these results can also be used for counseling, coaching, and mentoring.

Further, the organization can tap the personal characteristics and strengths that underlie the manager's transformational behavior. Charismatic leaders are characterized by energy, self-confidence, determination, intellect, verbal skills, and strong ego ideals. Each of these traits can be assessed in individual managers. Similarly, we can assess some of ation, such as coaching skills; preference for two-way, face-to-face communication; and willingness to delegate. Again, in the area of intellectual stimulation, candidates for promotion could be assessed with an eye toward the type of intellectual stimulation-general, creative, or mathematical-that would be most effective at the higher level of management. Appropriate intelligence tests may be used to select intellectually stimulating candidates.

Research findings indicate that when employees rate their managers on the MLQ, they describe new business leaders as significantly more transformational than established business leaders. Thus MLQ scores can be used profitably to identify executives to head new ventures.

\section{Implications for Development}

A management trainee's first supervisor can make a big difference in his or her subsequent career success. For example, six years after they joined Exxon, many managers who were highly rated by their supervisors reported that they had been given challenging assignments by their initial supervisor (i.e., they had received individualized consideration). Many had been assigned to supervisors with good reputations in the firm. It is important to note that managers tend to model their own leadership style after that of their immediate supervisors. Thus if more higher-ups are transformational, more lower-level employees will emulate transformational behavior and will be likely to act as transformational leaders as they rise in the organization.

Organizational policy needs to support an understanding and appreciation of the maverick who is willing to take unpopular positions, who knows when to reject the conventional wisdom, and who takes reasonable 
risks. For example, when R. Gordon McGovern took over as president of Campbell Soup, he introduced the "right to fail" policy, which shook up the stodgy organization. On the other hand, the fine line between self-confidence and obstinacy needs to be drawn. The determined Winston Churchill who contributed so much to the survival of Britain in shown that leaders at all levels can be trained to be charismatic in both verbal and nonverbal performance. Successful programs have been conducted for first-level project leaders in hi-tech computer firms as well as for senior executives of insurance firms.

That transformational leadership can be increased through training was verified in

\section{GSTransformational leadership can be learned, and it can-and should-be the subject of management training and development. Re- search has shown that leaders at all levels can be trained to be charismatic. . .."}

1940 was the same Churchill whose obstinacy contributed to the mistakes in 1941 of failing to prepare Singapore adequately and of committing British troops to unnecessary disaster in Crete and Greece.

Intellectual stimulation also needs to be nurtured and cultivated as a way of life in the organization. The "best and the brightest" people should be hired, nourished, and encouraged. Innovation and creativity should be fostered at all levels in the firm.

\section{Implications for Training}

Despite conventional wisdom to the contrary, transformational leadership is a widespread phenomenon. True, more of it occurs at the top than at the bottom of an organization; but it has also been observed by many employees in their first-level supervisors. Transformational leadership can be learned, and it can - and should - be the subject of management training and development. Research has an experiment when Multifactor Leadership Questionnaire scores were obtained on shop supervisors from their trainees, who were inmates in minimum, medium, and maximum security prisons. The supervisors worked directly with the inmates in industrial shops to produce various products for sale within and outside the prison system. The experiment compared four groups of supervisors on their pre- and post-training effectiveness in various industrial and vocational shops in the prison. One group was trained in transformational leadership, one group was trained in transactional leadership, one was untrained but measured "before and after," and one was untrained and measured only "after." The performances of both trained groups improved, but in comparison to the three other groups of supervisors, those who were trained in transformational leadership did as well or better at improving productivity, absenteeism, and "citizenship" behavior among the inmates; they also won more respect from the inmates. 


\section{TRAINING MANAGERS}

Practical training that teaches people how to be transformational is similar to that used in the Xerox RPG strategy to modify management style. A counselor, mediator, or supervisor gives a manager a detailed, standardized description of his or her transformational and transactional leadership performance as rated by the manager's employees and/or colleagues. The Multifactor Leadership Questionnaire is used for this purpose. The manager also sees a chart showing the effects of his or her leadership on employee satisfaction, motivation, and perception of organizational effectiveness. Anonymity is maintained, although the manager sees the individual differences among the responses.

Participating managers complete a parallel questionnaire about their own leadership. The discrepancies between how they rate themselves and how their employees rate them may be examined scale-by-scale and item-by-item. The counselor may pose such questions as: "Why do you think you gave yourself a much higher score than your employees gave you in individualized consideration?" and "Why did your employees disagree with you on how rapidly you get to the heart of complex problems or the extent to which they trust you to overcome any obstacles?" It is important for managers to be aware of and accept their employees' view of their performance. A study of United States Naval officers found that those who agreed with their direct reports about their transformational leadership behavior were also likely to earn higher fitness ratings and recommendations for early promotion from their supervisors.

The manager and the counselor discuss in detail why certain results may have appeared and what can be done to improve ratings. For example, a manager may be asked: "What employees say they are proud to work with you?" or "What have you done that results in your colleagues' saying you foster a sense of mission?" The collected responses to these questions can create a useful picture of what the manager can do to raise his or her performance on particular items.

In addition to working individually with a counselor, the manager also may participate in a workshop with other managers who are working toward becoming more transformational leaders. Workshop participants who received high ratings from their employees on a particular item are asked what they, the participants, specifically did to achieve these ratings. Questions might include: “Why did all of your employees say that you frequently enabled them to think about old problems in new ways?" or "Why did they all say that you increased their optimism for the future?"

Conversely, questions may focus on why a participant's employees varied widely in their ratings. If the data printout shows a wide divergence of opinion about whether a manager made the employees enthusiastic about assignments, he or she might be asked to suggest possible reasons for such differences of opinion among the employees.

\section{Other Approaches to Training}

Several other approaches to teaching transformational leadership make use of the specific data gathered in the workshop. For instance, participants are asked to think of an effective leader they have known and the behavior the leader displayed. Many examples of charisma, individualized consideration, and intellectual stimulation are usually noted. The effective leaders who are mentioned typically come from many levels inside and outside the organization; the workshop leader may point out that transformational leader- 
ship is neither particularly uncommon nor limited only to world class leaders. Moreover, these leaders' specific behaviors can be described, observed, and adopted. After viewing videotapes of charismatic, individually considerate, and intellectually stimulating managers in action, workshop participants may be asked to create their own scenarios and videotapes, in which they emulate the transformational leaders they have observed. The other participants may then offer critiques and suggest improvements.

The workshop also aims to increase other aspects of transformational leadership. The transformational leader develops and changes the organizational culture, and to show participants that they have such capabilities, the
- I am going to sit down with all my employees and review these data with them.

- I am going to ask for another "reading" in a year; in the meantime I will try to reduce the discrepancies between where I am and where I should be.

- I'm going to talk with my mentor about these results and ask him what he thinks I should do about them.

Implications for Leadership Education

Military academies have traditionally emphasized leadership education, and today we are seeing a surge of interest in leadership courses in liberal arts colleges as well. At least

\section{$\checkmark \checkmark A$ counselor, mediator, or supervisor gives a manager a detailed, standardized description of his or her transformational and transac- tional leadership performance as rated by the managers' employees and/or colleagues."}

workshop leader asks them to imagine what the organization might be like in two to five years if it were fully aligned with their own ideas and interests. Then, in small teams based on their actual functions at work, they proceed to redesign the organization.

Similarly, training in mentoring can be used to promote the transformational factor of individualized consideration. For example, one participant can counsel another while a third acts as an observer and a source of feedback about the performance. And many creativity exercises show a manager how he or she can be more intellectually stimulating. Action plans emerge from workshop sessions. Examples include the following:
600 such courses were being offered, according to a recently completed survey of colleges. The Center for Creative Leadership holds conferences on leadership courses in undergraduate education, most recently in the summer of 1986. The subject of transformational leadership also has been added to leadership courses at the U.S. Air Force Academy at Colorado Springs. In one such course, both faculty and students examined how Air Force officers who are transformational leaders serve as role models for cadets. Scales from the Multifactor Leadership Questionnaire were used to show that the transformational leaders among the instructors and staff provided role models for their students. The 
faculty and students discussed the questionnaire results and their implications.

Clearly, training cannot turn a purely transactional leader into a transformational leader. Moreover, some managers, while striving to be transformational leaders, misuse their training; their pseudotransformational efforts only further the manager's self-interest and values. Under the influence of such a manager, employees can be misdirected away from their own best interests and those of the organization as a whole. In one such case, Donald Burr of People's Express Airlines displayed many transformational qualities that rapidly built and then rapidly ruined the firm.

For too long, leadership development has been seen as mainly a matter of skill development. But leadership - particularly transformational leadership - should be regarded as an art and a science. It is encouraging to see that the Council for Liberal Learning of the Association of American Colleges now sponsors week-long conferences on leadership for scholars, prominent citizens, and national leaders.

\section{Implications for Job Design and Job Assignment}

As we have noted earlier, the results of a study of Exxon managers showed that highly rated managers had had challenging tasks delegated to them by their supervisors when they first joined the company. Jobs can - and should - be designed to provide greater challenges. Delegation with guidance and followup can become an individualizing and developmental way of life in a firm.

Transformational leaders show individualized consideration by paying attention to the particular development needs of each of their employees. Employees' jobs are designed of the organization. One employee needs experience leading a project team. Another needs an opportunity to reinforce what she has learned in an advanced computer programming class. Their transformational leader assigns them tasks accordingly.

Leaders can be intellectually stimulating to their employees if their own jobs allow them to explore new opportunities, to diagnose organizational problems, and to generate solutions. Leaders whose jobs force them to focus on solving small, immediate problems are likely to be less intellectually stimulating than those who have time to think ahead and in larger terms.

\section{Implications for Organizational Structure}

Transformational leadership is not a panacea. In many situations, it is inappropriate and transactional processes are indicated. In general, firms that are functioning in stable markets can afford to depend on their "oneminute" managers to provide the necessary, day-to-day leadership. If the technology, workforce, and environment are stable as well, then things are likely to move along quite well with managers who simply promise and deliver rewards to employees for carrying out assignments. And in stable organizations, even management-by-exception can be quite effective if the manager monitors employee performance and takes corrective action as needed. Rules and regulations for getting things done, when clearly understood and accepted by the employees, can eliminate the need for leadership under some circumstances.

But when the firm is faced with a turbulent marketplace; when its products are born, live, and die within the span of a few years; and/or when its current technology can be- 
come obsolete before it is fully depreciated; then transformational leadership needs to be fostered at all levels in the firm. In order to succeed, the firm needs to have the flexibility to forecast and meet new demands and changes as they occur-and only transformational leadership can enable the firm to do so.

Problems, rapid changes, and uncertainties call for a flexible organization with determined leaders who can inspire employees to participate enthusiastically in team efforts and share in organizational goals. In short, charisma, attention to individualized development, and the ability and willingness to provide intellectual stimulation are critical in leaders whose firms are faced with demands for renewal and change. At these organizations, fostering transformational leadership through policies of recruitment, selection, promotion, training, and development is likely to pay off in the health, well-being, and effective performance of the organization.

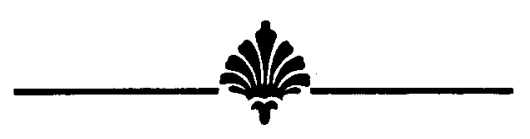

\section{SELECTED BIBLIOGRAPHY}

For nontechnical reading about transformational and transactional leadership, the following are suggested: James MacGregor Burns's Leadership (Harper, 1978); Bernard M. Bass's Leadership and Performance Beyond Expectations (Free Press, 1985) and "Leadership: Good, Better, Best" (Organizational Dynamics, 1985); Noel Tichy and Michelle Devanna's Transformational Leadership (Wiley, 1986); Warren G. Bennis and B. Nanus's Leaders: The Strategies for Taking Charge (Harper \& Row, 1985); and Jan M. Kouzes and Barry Z. Posner's The Leadership Challenge: How to Get Extraordinary Things Done in Organizations (JosseyBass, 1987).

For more on transformational leadership that is selfish or antisocial, see Bernard M. Bass's "The Two Faces of Charismatic Leadership" (Leaders Magazine, forthcoming) and Jane Howell's "Two Faces of Charisma: Socialized and Personalized Leadership in Organizations" in Charismatic Leadership: The Illusive Factor in Organizational Effectiveness (Jossey-Bass, 1988), edited by Jay A. Conger and Rabindra N. Kanungo and Associates.

Several articles provide more specific evidence about and applications of transformational leadership. These include Bruce J. Avolio and Bernard M. Bass's "Charisma and Beyond," in Emerging Leadership Vistas, edited by Jerry G. Hunt (Lexington Books, 1988); Bernard M. Bass, Bruce J. Avolio, and Laurie Goodheim's "Biography and the Assessment of Transformational Leadership at the World Class Level" (Joumal of Management, Volume 13, 1987); and John Hater and Bernard $M$. Bass's 'Superiors' Evaluations and Subordinates' Perceptions of Transformational and Transactional Leadership" (Journal of Applied Psychology, November 1988).

Other very useful articles include Richard Crookall's "Management of Inmate Workers: A Field Test of Transformational and Situational Leadership" (Ph.D. dissertation, University of Western Ontario, 1989); and David A. Waldman, Bernard M. Bass, and Francis J. Yammarino's "Adding to Leader-Follower Transactions: The Augmenting Effect of Charismatic Leadership" (Technical Report 3, Center for Leadership Studies, State University of New York, Binghamton, 1988). A detailed review of findings is presented in Bernard M. Bass and Bruce J. Avolio's "Implications of Transactional and Transformational Leadership for Individual, Team and Organizational Development" in Research in Organizational Change and Development, edited by Richard W. Woodman and William A. Pasmore (JAI Press, 1989).

If you wish to make photocopies or obtain reprints of this or other articles in Organizarional Drnamics, please refer to the special reprint service instructions on page 80 . 